\title{
"Lavar la Deshonra": Una aproximación a los femicidios en nombre del honor
}

\author{
"Lavar la Deshonra": An approach to femicides in the name of honor
}

\section{MAYRA SOLEDAD VALCARCEL*}

Resumen: El presente artículo constituye una introducción a los "crímenes de honor". Incluye un relevamiento de carácter general sobre la bibliografía existente - en su mayoría en inglés-, así como también una aproximación a las principales líneas de discusión e investigación en torno esta temática. A su vez, proponemos una lectura situada de esta problemática a partir del diálogo entre trabajos que abordan otras formas de violencia de género con el propósito de descubrir y analizar las continuidades y rupturas entre estas distintas manifestaciones. Reflexionando respecto al rol simbólico e instrumental del cuerpo femenino y/o feminizado en la construcción de diversas comunidades (familiar, étnica, nacional, religiosa, étc) y las tramas discursivas (normativas y emotivas) que configuran y legitiman expresiones particulares y contextuales de violencia contra las mujeres.

Palabras Clave: Crímenes de honor, género, moralidad, cuerpo, violencia

\begin{abstract}
This article constitutes an introduction to "honour crimes". It includes a review about the current bibliography - mostly of it in english -, as well as an approximation to the main lines of discussion and research. At the same time, we propose a situated reflection about this problematic starting from the dialogue between works that report other forms of gender violence with the purpose of analyzing the continuities and ruptures between these different manifestations. Reflecting on the symbolic and instrumental role of the feminine and feminized body on the construction of diverse communities (family, ethnic, national, religious, etc.) and the discursive plots (normative and emotive) that configure and legitimize specific and contextual expressions of violence against women.
\end{abstract}

Keyword: Honour crimes, gender, morality, body, violence

\footnotetext{
* Mayra Soledad Valcarcel: Universidad de Buenos Aires, Buenos Aires, Argentina. Código ORCID: org/0000-0002-2731-833X Contacto: mayravalcarcel@yahoo.com.ar
} 
Vecinas del barrio, chicas del pueblo, amasaremos el pan con nuestras lágrimas, nos cortaremos las trenzas, nos decoloraremos las manos para que sus ropas permanezcan blancas y puras. No sonreiremos ni nos alegraremos ni nos giraremos porque el puñal, en la mano de nuestro padre o de nuestro hermano, nos vigila y mañana, ¿Quién sabe en qué desierto nos enterrará para lavar la deshonra?

"Lavar la Deshonra”, Nazik al Malaika ${ }^{1}$

\section{Introducción}

$\mathrm{E}^{1}$ constructo muslimwoman ${ }^{2}$ (Cooke, 2007) se ha convertido, y no carente de intencionalidad, en un fetiche entre y dentro de los discursos neorientalistas e islámicos. Circulan diversos estereotipos que refuerzan el modelo de choque de civilizaciones y reactualizan las fantasías coloniales (Yeğenoğlu, 1998). Las mujeres musulmanas pueden ser representadas como mujeres exóticas, peligrosas (asociación con el terrorismo), piadosas, castas o víctimas sumisas e indefensas de sus esposos, padres, hermanos y comunidades. Estereotipos y estigmatizaciones que reproducen la subalternización dentro y fuera de sus comunidades de pertenencia. Aquellos que algunas autoras denominan islamofobia generizada (Zine, 2006, 2008).

Temas como la ablación de clítoris, la lapidación ${ }^{3}$ y "los crímenes honor" despiertan la curiosidad y conmoción de la opinión pública en sociedades occidentales, pero poco se conoce, especialmente en estas latitudes, sobre estas problemáticas por fuera de los discursos e imágenes sensacionalistas (Gill, Begikhani y Hague, 2012). En esta oportunidad, proponemos realizar un breve estado de la cuestión sobre los mal llamados "crímenes de honor" (qué son, y porqué se reducen -erróneamente- a una práctica islámica) y relevar grosso modo las líneas de análisis que se desprenden de la bibliografía que aborda este fenómeno (Kulczycki y Windle, 2011; Gill, 2013; Gill, Strange y Roberts, 2014).

\footnotetext{
${ }^{1}$ Poetisa iraquí (1923-2007). Fragmento perteneciente al poemario El hueco de la ola (1957).

${ }^{2}$ Neologismo que une (sin guiones) en una misma categoría los términos muslim y woman. Es utilizado por Miriam Cooke para referirse a las construcciones que evocan una identidad única, singular y homogénea entre las mujeres musulmanas (2007, p. 91).

${ }^{3} \mathrm{Al}$ respecto sugerimos la lectura de los artículos de Moualhi (2000) y Warren (2008) que confrontan los presupuestos existentes en torno, entre otros temas, a la ablación de clítoris, la lapidación, y el uso del velo.
} 
Los "crímenes de honor"4 (honour killings) constituyen un tipo de femicidio extendido en muchos países de Asia y África. Coincidimos, por supuesto, con las autoras que afirman que dicha denominación es un oxímoron ya que no puede hallarse nada honorable en los asesinatos (Meetoo y Mirza, 2007; Sev'er y Yurdakul, 1999). Debemos emprender con esta denominación una tarea de deconstrucción y desnaturalización similar a la realizada con los "crímenes pasionales" en América Latina. El Fondo de Población de Naciones Unidas estima que se perpetran más de 5.000 crímenes ${ }^{5}$ de honor por año en el mundo (Welchman y Hossain, 2005, citado en Gil, Begikhani y Hague, 2012, p. 72), aunque, estas cifras podrían engrosarse considerablemente teniendo en cuenta los casos no reportados como la falta de estadísticas nacionales e internacionales oficiales al respecto.

El crimen en defensa del honor, como bien señala Anissa Hélie (2012), es un patrón de conducta (una forma de violencia de género) que existe en distintas comunidades. No se reducen a una problemática exclusivamente musulmana o propia de los contextos musulmanes. No se encuentran prescriptos en el Corán; libro sagrado que, además, condena enfáticamente el asesinato. Como sostienen Sev'er y Yurdakul (1999) no es necesario referirse al islam o a cualquier otra religión para entender y analizar la epistemología del asesinato de una mujer en "nombre del honor".

Sería imposible describir y caracterizar el sistema sexo/género islámico en toda su complejidad al igual que ahondar en las distintas interpretaciones. Nos podemos encontrar con enfoques "islamistas" y "(neo)tradicionalistas" como con revisiones hermenéuticas progresistas y feministas. Cuando nos referimos al islam debemos considerar no sólo la gran diversidad de corrientes, escuelas de pensamiento y jurisprudencia, sino, también, sus múltiples geografías y expresiones locales (Hefner, 2011, p. 14). Se ha extendido históricamente a través de territorios árabes, el norte de África, los Balcanes, regiones del mundo indo-iraní y el sudeste asiático. Además, de la presencia contemporánea de numerosas e importantes comunidades en América y Europa.

Dicho esto, quisiéramos enfatizar dos aspectos. Por un lado, la pluralidad y diversidad del mundo islámico. Por esta misma razón, hablar de la "mujer musulmana" es - como bien señala Homa Hoodfar (1998) - una abstracción histórica que conduce a la simplificación de la diversidad y la homogeneización de prácticas culturales y sociales como las distintas formas en que las creyentes experimenta el $\mathrm{din}^{7}$ o enfrentan las normas; impidiendo así el diálogo y solidaridad entre mujeres. Divisiones que favorecen, ratifica

\footnotetext{
${ }^{4}$ Por más información recomendamos leer la siguiente publicación digital de Vanessa Alejandra Rivera de la Fuente: http://www.unitedexplanations.org/2014/07/21/peligro-muerte-mujeres-que-se-rebelan-contrael-honor-familiar/

5 En el sitio web: Honour Based Violence Awareness Network: http://hbv-awareness.com/

6 Término en discusión. Algunos/as autores/as prefieren hablar de Islam Político, mientras otros/as redefinen la categoría de Islam Político de forma tal que incluye en su seno tendencias progresistas como aquellas más "ortodoxas".

7 Los/as musulmanes/as entienden que el islam es más que una religión. Es una forma de vida que comprende todos los aspectos individuales y sociales (economía, higiene, moral, justicia social, política, étc). El din islámico es un sistema multifacético.
} 
Hoodfar, los intereses del patriarcado (ibid, p. 2). Por el otro, la necesidad de complejizar la aproximación a esta forma de femicidios. Evitar su simplificación a una norma o práctica religiosa que no hace más que desconocer las variables y tramas de legitimación e inteligibilidad de la violencia de género; contribuyendo, además, a la demonización del islam, de otras sociedades y comunidades étnicas y religiosas (Gill y Brah, 2014). Autoras como Gill, Begikhani y Hague prefieren directamente reemplazar el término violencia basada en el honor (Honour-Based Violence, HBV) por violencia contra la mujer (Violence against Women, VAW) ya que consideran que el honor es un concepto intrínsecamente problemático ya que se asocia directamente al comportamiento humano como a la exotización y el esencialismo cultural (2012, p. 75). Sostienen que el honor y la vergüenza como anverso del mismo fenómeno - no se encuentran controlados por una institución centralizada, sino que, por el contrario, son nociones complejas que se van transformando y resignificando constantemente.

\section{Corpografías de la violencia: género, comunidad y honor}

La violencia contra o hacia las mujeres no es un fenómeno nuevo, pero sí lo es el significado social que se le atribuye actualmente (Miguel Álvarez, 2003). Las Ciencias Sociales, los Estudios Feministas junto al aporte y la militancia de colectivos y activistas, han contribuido en la visibilización de distintas formas de violencia. Recordemos, por ejemplo, el modo en cómo se definió la “discriminación contra la mujer" en el $1^{\circ}$ artículo de la CEDAW ${ }^{8}$ en 1979 y que será recién en la Conferencia Mundial sobre Mujer y Desarrollo llevada a cabo en Beijing en 1995 cuando, retomando el $1^{\circ}$ artículo de la Declaración sobre la Eliminación de la violencia contra las Mujeres ${ }^{9}$ aprobada en 1993, se logre conceptualizar la violencia de género como tal.

Se vuelve indispensable, por lo tanto, distinguir y relacionar distintos niveles y dimensiones de esta violencia. No sólo aquellas expresiones brutales que impactan en la agenda social y mediática. Si no, también, aquellas mucho menos tangibles e identificables por ser aceptadas, toleradas o disimuladas culturalmente. Formas, quizás, más elípticas y subterráneas. Pero todas ellas mutuamente implicadas dentro de sistemas locales, nacionales e internacionales cada vez más fracturados, opresivos y desiguales.

En esta línea, podríamos recuperar - tal como lo hace Carmen Magallón Portolés (2005) - el modelo triangular de Johan Galtung (1990) para reconocer y señalar la coexistencia e implicación de tres formas de violencia que afectan las necesidades de supervivencia, de bienestar, de libertad, de identidad y representación de las personas en general y las mujeres en particular. Identificar la violencia directa la cual podríamos

\footnotetext{
${ }^{8}$ Convención para la Eliminación de todas las formas de Discriminación Contra la Mujer.

9 En el primer artículo se define la violencia contra la mujer como "todo acto de violencia basado en la diferencia de género que tenga o puede tener como resultado un daño o sufrimiento físico, sexual o psicológico para la mujer, inclusive la amenaza de tales actos, la coacción o la privación arbitraria de la libertad, tanto si se producen en la vida pública como privada". Disponible en http://www.un.org/es/comun/docs/?symbol=A/RES/48/104
} 
ejemplificar con la violación sexual o el femicidio ${ }^{10}$. La violencia estructural la cual define como el proceso social y político-institucional en cuyo centro se encuentra la explotación. Inmediatamente se nos viene a la mente la posición subordinada de la clase obrera, las mujeres y minorías étnicas. Estos grupos son, en palabras de Nancy Fraser (2008), colectividades bivalentes. El género, al igual que la raza, es una diferencia social bidimensional: una categoría híbrida que combina una desigual distribución en la estructura política-económica como un erróneo reconocimiento en el plano culturalvalorativo. En último lugar, la violencia cultural o simbólica en la que Galtung engloba la religión, el lenguaje, la educación, el arte y la ciencia.

No podemos, entonces, cuando hablamos de los "crímenes en nombre del honor" pasar por alto que el carácter isomorfo, complejo, dislocado y yuxtapuesto de los diversos paisajes (Appadurai, 2001) que componen la economía cultural global y que favorecen la preservación de algunas expresiones de violencia, aunque también la adquisición de nuevos ropajes o la teatralización y espectacularización de sus formas ya conocidas. Segato nos habla, por ejemplo, de la informalidad y privatización de los conflictos, pero simultáneamente su duplicidad y para-estatalidad (2014, p. 43). Se desarrollan en espacios intersticiales de bajos niveles de formalización y con una pluralización de actores en juego (sicariatos, grupos fundamentalistas, agentes estales, entre otros); desplegando la pedagogía de la crueldad ${ }^{11}$ como forma de evidenciar el control territorial (ibíd., p. 56).

En este sentido, deberíamos considerar a la hora de abordar los "crímenes de honor" la desigualdad y brecha de género en todos los campos (patrimonial, educativo, sanitario, etc.) de las sociedades en los que prevalecen; el impacto de movimientos islamistas, fundamentalismos y nacionalismos en los distintos contextos; la situación de las comunidades diaspóricas, étnicas y religiosas en sociedades occidentales; así como también la existencia de conflictos cívico-militares, étnico-religiosos e, incluso, bélicos

\footnotetext{
${ }^{10}$ Algunas autoras, como Marcela Lagarde, emplean el término feminicidio mientras otras prefieren, en cambio, el vocablo femicidio. La palabra feminicidio recién fue incluida por la RAE para la $23^{\mathrm{a}}$ edición del Diccionario de la Lengua Española hacia 2014 cuando el término original en inglés (femicide) fue utilizado por Diana Russel el año 1976 en el Tribunal Internacional de Crímenes contra Mujeres en Bruselas para referirse a los asesinatos misóginos como crímenes de odio. Años más tarde, en 1990, Russel junto a Jane Caputi definieron el femicidio (femicide) como "el asesinato de mujeres realizado por hombres motivados por odio, desprecio, placer o un sentido de propiedad de las mujeres" (citado en Russel y Harmes, 2006, p. 77). Caputi y Russel (1990) afirman lo siguiente: "Murder is simply the most extreme form of sexism terrorism. A new word is needed to reflect this political understanding. We think femicide best describes the murders of women by men motivated by hatred, contempt, pleasure, or a sense of ownership of women. Femicide includes mutilation, murder, rape murder, battery that escalates into murder; historical immolation of witches in Europe; historical and contemporary immolation of brides and widows in India; and "honor crimes" in some Latin and Middle Eastern countries, where women believed to have their lost their virginity sometimes are killed by male relatives". Caputi, J., \& Russell, D. E. (1990). "Femicide: speaking the unspeakable". MS Magazine, 1, $n^{\circ} 2$, pp. 34-37. Por más, léase: Lagarde, Marcela (2006). "Del femicidio al feminicidio". En Desde el Jardín de Freud, n ${ }^{\circ}$ : pp. 216-225.

${ }^{11}$ Segato se refiere a las nuevas formas de crueldad y brutalidad despiadada contra aquellos que no tienen el rol de antagonistas en los conflictos armados o enfrentamientos. Es decir, las mujeres, niñas, niños y todos aquellos cuerpos feminizados (2014, p. 15). Existe, en especial, una rapiña sobre lo femenino. A saber: formas de ocupación, destrucción y comercialización de los cuerpos femeninos (ibíd., p.17). Los agredidos son "los cuerpos frágiles" y "tutelados". Sus cuerpos son el "soporte en que se escribe la derrota moral del enemigo" (ibíd., p. 23).
} 
en los que intervienen distintos agentes geopolíticos locales (estatales, paraestatales, civiles, religiosos) e internacionales (tropas militares, ONGs, etc.).

El desafío consiste, por ende, en vislumbrar las particularidades que manifiestan los "crímenes de honor" sin promover una visión que revictimice a las mujeres y comprendiéndolos dentro un intrincado entramado de cartografías y topografías de la crueldad configuradas a escala local y transnacional (Balibar, 2001). Desentrañar, recuperando la perspectiva comparativa y reflexión transcultural de la antropología, el rol que desempeña metafórica o metonímicamente el cuerpo de la mujer en la construcción de las distintas comunidades imaginadas ${ }^{12}$ y su presunta "honorabilidad", "moralidad", "pureza" e "identidad".

La masculinidad protectora y galante necesita de una femineidad dependiente (Young, 2003) y, a su vez, de "la masculinidad aberrante del otro" (Stanley, 2007). Esta lógica paternalista se replica tanto en el plano de las relaciones familiares y personales como en la sociedad nacional; revestida en ambos casos tras la figura del "hogar". Pensemos, por ejemplo, en la militarización y remasculinización de la sociedad norteamericana luego del 11 de septiembre (Sharp, 2005). El lenguaje del heroísmo (proteger la nación dañada y salvar a las mujeres y niños/as afganos/as) ayudó a consolidar la dicotomía público-privado y su correlativa división entre lo nacional y lo internacional. O recordemos las guerras en la ex Yugoslavia y Ruanda ${ }^{13}$ que marcaron un nuevo paradigma de la acción bélica en el que la agresión sexual deja de ser un efecto colateral de los conflictos y se convierte, en cambio, en un objetivo estratégico de los mismos (Segato, 2014, p. 18). Si bien el nivel de violencia sexual no sigue siempre un patrón simétrico o proporcional a la intensidad y magnitud general del conflicto (cantidad de muertes y víctimas) analizado (Wood, 2009); ésta se convierte en una tecnología sexual de guerra (Nagel, 2003).

Los conflictos cívico-militares siempre son acompañados por una expresión intensificada del orden de género (Stanley, 2007, p. 11). La militarización de la heterosexualidad en la que los otros son percibidos y definidos como promiscuos, subsexuados o sobre-sexuados descansa en el carácter etnosexual de las fronteras territoriales y simbólicas (Nagel, 2003). Por eso, para Nagel violencia sexual constituye simultáneamente: a) una técnica del terror contra las mujeres, b) una acción de "contaminación” individual y colectiva y c) un mecanismo de transacción entre hombres. En sintonía, no es casual que, junto a la violencia sexual, la destrucción de la procreación ajena y el fomento de la natalidad propia se presenten como el anverso y reverso de un mismo proceso (Frigolé, 2009).

\footnotetext{
${ }^{12}$ Retomamos la definición realizada por Benedict Anderson en Comunidades Imaginadas: Reflexiones sobre el origen y difusión del Nacionalismo. México: FCE, 1993.

13. Se estiman entre 250.000 y 500.000 violaciones sistemáticas en Ruanda. Las violaciones de las mujeres Tustsi en Ruanda fueron clasificadas como una forma de genocidio por el Tribunal Criminal Internacional en 1998 y las violaciones perpetradas por los militares serbios contra las mujeres albanesas y bosnias musulmanas a quiénes mantenían en cautiverio hasta que fuese imposible la interrupción del embarazo con el objetivo de engendrar bebés cetnik (serbios), han sido clasificados por el derecho internacional como crímenes de lesa humanidad. Muchas autoras denominan los crímenes institucionalizados como los de Ruanda y Bosnia como femigenocidio (Russel \& Radford, 2006; Segato, 2010)
} 
En suma, los cuerpos femeninos (y feminizados) son el bastidor ${ }^{14}$ en el que se inscribe la violencia (entre familias, tribus, pandillas, sicariatos e, incluso, la estructura de la guerra) debido al imaginario ancestral que encarna (Segato, 2014:58). La histórica inscripción de la "nación" en los cuerpos de las mujeres; éstos como repositorios de la distinción cultural y religiosa (Bannerji, 1994; Chatterjee, 1993; Kandiyoti, 1991; YuvalDavis, 1997) y, por ende, la revitalización de los discursos del honor y la culpa (Feldman, 2010, p. 75) Pero ¿qué sucede cuándo a través del cuerpo-bastidor femenino no se trama la destrucción del enemigo o su "contaminación" sino, en cambio, el acto sacrificial que restituye el propio "honor", "pureza" ${ }^{15}$ y "vergüenza?

\section{Criminalización de la sexualidad femenina: religión, cultura y política}

Existen distintas geografías del islam, es decir, múltiples comunidades y sociedades musulmanas a lo largo y ancho del globo. Sin embargo, esta diversidad se pierde de vista y los "crímenes de honor", especialmente los cometidos en Europa o América del Norte son utilizados para reavivar la teoría del choque de civilizaciones y la construcción de imaginarios (neo)orientalistas en torno a la otredad étnica y/o religiosa (Gill y Brah, 2014; Sanberg y Janssen, 2018). Han sido, por ejemplo, muy difundidos femicidios como el de Aqsa Parvez ${ }^{16}$ en Canadá en el año 2007. Una joven de tan sólo 16 años asesinada por su padre supuestamente porque se negaba a usar el hiyab. O el caso de Fadime Šahindal ${ }^{17}$ en Suecia en el año 2002. Fadime era una joven de origen kurdo que en 1996 inició una relación con un muchacho sueco lo que desencadenó en un conflicto con su padre y hermano. Recibió amenazas por parte de los miembros masculinos de su familia y en el año 1998 su pareja fue asesinada. Posteriormente, participó de distintas campañas para concientizar sobre la violencia contra las mujeres hasta que en el año 2002 fue asesinada por su padre.

Este trágico evento reavivó - señalan Mojab y Hassanpour - la idea del choque de civilizaciones: la demonización de los hombres kurdos en particular y la estigmatización de la cultura kurda en general (2003, p. 59). Se creó el mito de que la violencia contra las mujeres es producto de la "subcultura" de los inmigrantes. Algo similar ocurre con la comunidad turca en Alemania o bangladesí y pakistaní en el Reino Unido. Esta política eurocéntrica es exacerbada por los medios de comunicación; alentando tendencias racistas y xenófobas y consolidando una visión neocolonialista del mundo (ibíd., p. 65). Sanberg y Janssen (2018), por ejemplo, analizan - retomando a Hall y Maollem - el impacto de literatura autobiográfica de mujeres migrantes que relatan sus historias de

\footnotetext{
${ }^{14}$ Metáfora textil: el cuerpo de la mujer como Texto y Territorio (Gago y Gutiérrez en Segato, 2014, p. 5)

${ }^{15}$ Retomamos la definición heredada de los ya clásicos trabajos de Mary Douglas $(1973,1988)$.

${ }^{16}$ Por más, léase: Brooklynn Welden (2010).

${ }^{17} \mathrm{Se}$ pueden visitar los siguientes sitios elaborados en su memoria: http://www.iranbulletin.org/Hammed\%20Shahidian_mojab.htm y http://www.kvinnonet.org/essays/EN0041.html
} 
violencia en nombre del honor como una forma de "espectáculo de la otredad femenina" en tiempos de social media.

Nos encontramos con visiones esencialistas que consideran a las culturas y religiones como bloques monolíticos y desconocen las trayectorias de resistencia dentro de las comunidades. Mojab y Hassanpour (2003) sostienen que la cultura patriarcal es universal y que, por lo tanto, el dividir culturas entre aquellas que son violentas y aquellas que no lo son, no es más que otro mito patriarcal (2003, p. 60). Así mismo, explican que el nacionalismo kurdo - como cualquier otro - tiene sus contenidos androcéntricos, pero que también existen distintas tendencias ${ }^{18}$. Razón por la cual no se puede desconocer su diversidad ni la historia de las mujeres kurdas quienes, por ejemplo, en 1919 fundaron su primera organización o en la actualidad conformaron la Kurdish and Middle Eastern Women's Organisation ${ }^{19}$ en Gran Bretaña. Sin olvidarnos tampoco del rol que hoy en día tienen las combatientes kurdas de Kobane frente DAESH o el llamado "Estado Islámico" (ISIS).

Estas construcciones monolíticas exhiben las dificultades del multiculturalismo, especialmente a la hora de enfrentar el problema de la violencia contra las mujeres. Se construye una falsa dicotomía comunidad versus mujer desde distintos sectores; perdiendo de vista que - tratándose de violencia de género - en todas las sociedades intervienen distintos factores y causas. Estas visiones estrechas y etnocéntricas sobre las "minorías" demuestran, en palabras de Aisha Gill (2006), la hipocresía existente en lo que respecta a las prácticas y relaciones de género. En Europa, por ejemplo, se instaló la idea de que los "crímenes de honor" se convirtieron en una "epidemia" en el continente por culpa de las poblaciones migrantes; legitimando el mainstream de la presunta superioridad moral occidental ${ }^{20}$ (ibíd., p. 3).

La violencia queda reducida a tradiciones culturales o prácticas religiosas. Los "crímenes de honor", por ejemplo, son "étnicizados" (ethnicized) en un contexto multicultural británico que se imagina como una "comunidad de comunidades" (Meetoo y Mirza, 2007). La estigmatización es reproducida por la prensa sensacionalista y amarillista que fomenta la ansiedad y el temor hacia la "otredad". Meetoo y Mirza (2007) se refieren al tratamiento que los medios ingleses hacen de estos crímenes como "pornografía de la violencia". Al mismo tiempo, señalan que un multiculturalismo ciego al género invisibiliza las distintas expresiones de violencia contra las mujeres. El discurso multiculturalista plantearía la construcción de puentes para resolver los problemas entre las comunidades, pero no aquellos existentes al interior de cada una de ellas. Falla, dicen las autoras, al no analizar la yuxtaposición de los sistemas de opresión al que están expuestas las mujeres ni la interseccionalidad de sus construcciones identitarias. Ellas quedan atrapadas en una colisión de discursos e imaginarios (relativistas, esencialistas,

\footnotetext{
${ }^{18}$ Por ejemplo, el poeta kurdo Abdullah Goran (1904-1962) escribió un poema titulado "A Tombstone" (Berde-nûsêk) en el que condenaba los crímenes de honor. Su versión en inglés se puede consultar en: http://kurdishfeminists.com/page.php?id=797

${ }^{19}$ http://www.kmewo.com/

${ }^{20}$ Al respecto, es importante recordar los aportes de Chandra Mohanty (2008 [1984]) y Gayatri Spivak (2003[1985]) sobre la colonización discursiva y epistemológica de la academia y el feminismo occidental
} 
comunitarios, étc) que reproducen la falsa dicotomía mujer versus comunidad. $\mathrm{O}$, mejor dicho, los derechos de las mujeres versus los derechos comunitarios ${ }^{21}$.

En lo que refiere a los países de mayoría musulmana, la situación y el status de las mujeres se ha deteriorado notablemente desde que la colonización afectó disruptivamente el entramado social. Los órdenes o sistemas de género preexistentes se intensificaron o solidificaron mientras que se incorporaron (por imposición o adhesión) nuevos modelos y patrones sociosexuales. Las consecuencias del imperialismo y la desigual distribución de recursos del orden mundial afectaron, como siempre, especialmente a mujeres y niños/as de los países colonizados. No obstante, con el correr del tiempo, los procesos de descolonización, la consolidación de los Estados Nación y demás cambios políticos y económicos, se introdujeron algunas reformas que directa o indirectamente transformaron las relaciones de género en estas sociedades.

Pero entre los años '70 y '80, y en un contexto de crisis del neoliberalismo y de próxima consolidación de la globalización y el transnacionalismo, se desarrolla un movimiento político-religioso de gran complejidad, diversidad e impacto social que habitualmente se conoce como "resurgimiento islámico". Este movimiento tendrá muchas vertientes y manifestaciones. Varios autores se refieren a él como fundamentalismo islámico, algunos prefieren hablar de islamismo y otros, en cambio, ampliar el espectro del Islam Político. Más allá de lo difícil que resulte encontrar una categoría adecuada para denominar este fenómeno, podemos decir que algunas corrientes y grupos que se inscribirían dentro de este movimiento comparten una retórica - también presente en otros "fundamentalismos" religiosos, los fascismos y los nacionalismos militaristas - en la que el control sobre el cuerpo de la mujer, la familia y la moral sexual tradicional ocupan un lugar destacado (Imam, 1997; Marty y Appelby, 1993; Tarducci, 2002).

Estos movimientos, grupos y/o corrientes son selectivamente modernos y tradicionales. Construyen un sentido de la memoria que legitiman en base a un arquetipo (que puede ser la época del Profeta o extenderse a los cuatro primeros califas) pero que implementan a través de estrategias e instrumentos absolutamente contemporáneos. Se desarrolla un proceso complejo y dialéctico entre la politización de lo religioso y la sacralización de la política (Montenegro, 2007; Pace, 2006).

Persiguen la revitalización y reintroducción de la $\operatorname{sharia}^{22}$ (ley islámica), la cual interpretan desde una perspectiva completamente ahistórica, patriarcal y literal. Para los más radicales sólo es posible un gobierno teocrático porque la democracia se sostiene en la legislación humana mientras que el primero se fundamenta en la soberanía divina (Hefner, 2011, p. 6). Esta postura difiere sustancialmente de otros pensadores musulmanes contemporáneos ${ }^{23}$ que creen que los principios islámicos son totalmente

\footnotetext{
${ }^{21}$ Sobre los debates en torno al género y el multiculturalismo recomendamos consultar trabajos como los de María Xosé Agra Romero (2000), Rosa Cobo (1999), María José Guerra (2000) y Seyla Benhabib (2006) ${ }^{22}$ La sharia se conoce como la senda del islam (el camino correcto, ley divina) y es un código de conducta cuyas principales fuentes son el Corán y la Sunna (hadiz del profeta Muhammad).

23 Algunos de ellos son: Amina Wadud, Abdennur Prado, Muhammad Abdhuh, Fazhur Rahman, Abdolkarim Soroush y Nurcholish Madjid.
} 
compatibles con los preceptos democráticos y el discurso de los derechos humanos. Los teólogos reformistas y progresistas sostienen que la sharia no es inmutable ni monolítica. La sociedad de la revelación coránica no es la misma que la actual, y, por lo tanto, las normas deben adaptarse y ser flexibles. Reconocen la existencia de algunos objetivos mayores como el respeto a la vida y el conocimiento que deben mantenerse, pero que también hay determinados aspectos que pueden y deben reinterpretarse. Por consiguiente, defienden el derecho al ejercicio del ijtihad, es decir, a interpretar y reflexionar sobre las fuentes religiosas.

Entendemos que cualquier aplicación de la ley islámica es el resultado de una particular interpretación y, mejor dicho, instrumentalización de ésta. Para algunos autores la sharía no puede ser homologada a la ley occidental. Es, por el contrario, un discurso total (Asad, 1993; Messick, 1993). Y como tal impacta en todas las esferas de la vida y campos sociales.

Una de las nefastas consecuencias de la "revitalización de la sharia" es la reintroducción de las leyes zina (zina laws). Por ejemplo, Muhammad Ali Jinnah - figura relevante en la fundación de Pakistán - brindó un discurso en 1944 en el que reconocía la deplorable situación en la que se encontraban las mujeres y explicitaba que ninguna nación podría alcanzar su gloria si eso no se revertía (Hussain, 2006, p. 238). Sin embargo, décadas después, el General Muhammad Zia-ul-Haq - quien llega a la presidencia tras un golpe de Estado - introduce en 1979, con objeto de la "islamización" de la sociedad, las Ordenanzas Hudood. Estas ordenanzas definían, por ejemplo, que la violación era un crimen de adulterio; siendo considerado el embarazo producto del ultraje, la ratificación del delito de zina. Por lo tanto, la mujer víctima de violación era castigada según las ordenanzas hudud en lugar de ser protegida. Aunque Pakistán haya firmado la CEDAW (sin ratificar el protocolo opcional), la Declaración de los Derechos Humanos en el Islam ${ }^{24}$ (Cairo, 1990), y en el año 2006 haya aprobado la Ley de Protección de la Mujer ${ }^{25}$, como veremos en el próximo apartado, los "crímenes de honor" y la violencia contra las mujeres siguen siendo unas de las principales problemáticas que afectan dicho país.

Por otro lado, es interesante remarcar que sin importar qué corriente de pensamiento y jurisprudencia sigan estos grupos o, incluso, los regímenes teocráticos, la criminalización de la sexualidad es un elemento común entre todos ellos (Mir-Hosseini y Hamzić, 2010). Las leyes zina son parte de la tradición legal islámica y refieren al castigo que se aplica a la relación sexual que se practica fuera del seno matrimonial. El delito de zina constituye, según los juristas clásicos, uno de los crímenes hudud, es decir, una transgresión contra el derecho divino (su castigo aparece en el Corán) entre los que también se incluyen el robo y la apostasía.

\footnotetext{
${ }^{24}$ Puede consultarse en: http://amnistiacatalunya.org/edu/docs/e-mes-islam-1990.html ${ }^{25}$ Visitar http://english.ohmynews.com/articleview/article_view.asp?at_code=375584\&no=330818\&rel_no=1, 2511-2006,
} 
Adulterio y fornicación están condenados por la sharia, sin embargo, las características de la pena varían según el fiqh (jurisprudencia islámica). El Fiqh o derecho islámico es creado a partir de distintas interpretaciones de la ley islámica para su aplicación. Por consiguiente, su naturaleza es absolutamente contextual. Si las personas que comenten adulterio están casadas merecen, según algunas escuelas de pensamiento, la lapidación ${ }^{26}$. Aunque, para otras, el Corán sólo prescribe los latigazos y se requiere la confesión de los involucrados o el testimonio de cuatros testigos que ratifiquen haber presenciado el acto de ilaj (penetración). De lo contrario, serán acusados de falso testimonio. En el caso de personas solteras se habla del delito o pecado de fornicación y se castiga con latigazos para ambos implicados. Los pormenores de la pena como las discusiones en torno a su aplicación son muchísimas.

La complejidad de la temática nos impide explayarnos en esta oportunidad con la profundidad que amerita. Sin embargo, nos gustaría señalar que los casos de lapidación se encuentran raramente documentados en la historia de las sociedades musulmanas (MirHosseini y Hamzić, 2010, p. 21). De hecho, en 1680 el imperio otomano abolió la pena de lapidación. No obstante, en la actualidad nos encontramos que las leyes zina rigen oficialmente, es decir, constituyen la ley criminal, en países como Pakistán, Arabia Saudí e Irán, o, que, aunque la ley no esté basada absolutamente en el fiqh o combine códigos de tradición europea con preceptos la sharia, castigos similares sobre la mujer y sujetos LGTB siguen formando parte del derecho consuetudinario en muchas regiones. Es el caso, precisamente, de los "crímenes de honor".

\section{'A girl in the river": tramas de una configuración moral-normativa}

Tal como enfatizamos anteriormente, los denominados "crímenes de honor" no se circunscriben a una práctica o tradición étnica y/o religiosa. Sin embargo, debemos señalar que tienen mayor incidencia en algunos contextos que otros. Es el caso, por ejemplo, de Pakistán. En dicho país en el año 2011 fueron asesinadas 950 niñas y mujeres "en nombre del honor/ghariat" (karo kari como se los llama allí) y según Human Rights Commission of Pakistan, en el 2009 el 46\% de los asesinatos de mujeres correspondía a este tipo de femicidio (Hélie, 2012, p. 88). Las cifras pueden ser aún mayores. Según la Federación Internacional de Derechos Humanos en 2008 se calcularon entre 1200 y 1800 víctimas $^{27}$. Según un estudio de la División Nacional de Mujeres de Pakistán (Pakistan

\footnotetext{
${ }^{26}$ Es un tema controversial y sujeto a debate porque para muchos, el Corán prescribe los latigazos y la lapidación ha sido introducida a partir de interpretaciones sesgadas de un hadith del Profeta. Recordemos, además, que los hadith (tradiciones, dichos y consejos del Profeta) se aprecian y valoran según la legitimidad en la cadena de transmisión.

* A Girl in the River. The price of forgiveness (2015) es un corto documental dirigido por la periodista y activista pakistaní Sharmeen Obaid Chinoy que recupera el testimonio de Saba: una joven punjabi que sobrevivió al ataque perpetrado por su padre y tío luego de un "matrimonio no conveniente", siendo presionada por la comunidad para perdonarlos y cerrar la causa en su contra.

${ }^{27}$ En: Combatir los crímenes de honor en Europa: Manual para Responsables Políticos, Instituciones y la Sociedad Civil. Informe Fundación Surgir, Edición 2011/2012, Pp.12
} 
National Women's Division) la violencia en el espacio doméstico alcanza el $80 \%$ de las unidades familiares y la Comisión de Derechos Humanos de Pakistán afirma que en el país la violencia física alcanza al $65 \%$ de las mujeres, siendo un tercio de la misma violencia sexual (en Nasrullah, Haqqi y Cummings, 2009).

Algo similar ocurre en Jordania en donde en el año 2005 se registró que 1/3 de las muertes violentas se inscribían dentro de la lógica de los "crímenes de honor". El 90\% se cometen en base a rumores, chismes o "fabricación de acusaciones" que escondían, en verdad, otras situaciones de violencia intrafamiliar (Hussain, 2006, p. 225). En los albores del siglo XXI, el 25\% de los asesinatos en dicho país eran "crímenes de honor", de los cuales el $61 \%$ eran perpetrados por los hermanos de la víctima (Faqir, 2001). En la actualidad, a pesar del cambio de legislación, algunas periodistas reportan alrededor de 13 femicidios diarios en nombre del honor (Gill, Begikhani y Hague, 2012). Mientras que, en Turquía -por ejemplo- se reportan alrededor de 200 casos anuales. Según la Comisión especial para investigar estos crímenes, creada en el año 2006, entre ese año y 2010 se cometieron más de 332 femicidios. Estamos hablando de países de mayoría musulmana completamente diferentes entre sí. Sin embargo, la problemática se extiende en ellos al igual que en la India donde el islam, por ejemplo, no es la religión mayoritaria. Recordemos que también se han presentado numerosos casos, aunque en menor magnitud, en Inglaterra y otros países occidentales como vimos en el apartado anterior.

Es tal preocupación acerca de los "crímenes de honor" que en 2002 la Asamblea de la ONU aprobó la resolución 57/174 "Hacia la erradicación de los delitos de honor cometidos contra la mujer". Estos crímenes se inscriben dentro de un entramado de violencias basadas o "justificadas" en el honor que van desde la mutilación, el matrimonio forzoso, la incineración, la violación, hasta desencadenar en la muerte (por suicidio o asesinato). Los "crímenes de honor" no se englobarían, según algunas autoras, dentro la violencia doméstica (Keeping, 2012), aunque ésta los preceda; ni tampoco se ubicarían en la rúbrica de los "crímenes pasionales". Por el contrario, son femicidios planificados en los que participan distintos miembros varones de una familia y que, en algunas oportunidades, cuentan con la complicidad de otras mujeres.

La comunidad está implicada porque los legitima y los victimarios pocas veces se sienten arrepentidos ya que creen haber cumplido con su deber ${ }^{28}$. Nos recuerda, salvando las distancias, al trabajo de Godelier (1978) sobre los Baruya en Nueva Guinea en el que describe el monopolio masculino sobre ciertos saberes como el uso de un lenguaje cifrado. Allí explica que cuando una mujer ataca directamente un símbolo masculino, se le pide a algún miembro de su clan familiar que la asesine para de esta manera preservar la autoridad masculina; evitando -al mismo tiempo- futuras represalias entre los linajes de parentesco. Los hombres reaccionan como un cuerpo solidario y orgánico. En sintonía, y a pesar de las críticas feministas a la obra de Bourdieu (Acosta Martín, 2013; Moi, 2011; McNay, 2000; Perrot, 1998), algunas autoras retoman estas líneas teóricas para explicar los crímenes de honor a partir de los conceptos de habitus, dominación masculina y

\footnotetext{
${ }^{28}$ En: Combatir los crímenes de honor en Europa: Manual para Responsables Políticos, Instituciones y la Sociedad Civil. Informe Fundación Surgir, Edición 2011/2012, Pp.10
} 
eficacia simbólica (Grzyb, 2016); mientras que otras afirman que la violencia basada en el honor (HBV) sí debería ser entendida como una forma extrema de violencia doméstica contra la mujer (Aujla y Gill, 2014).

Mientras tanto, Rita Segato (2003) en su trabajo sobre la violación sostiene que la tensión constitutiva entre el sistema de status y el sistema de contrato es, precisamente, una de las estructuras elementales de la violencia de género. Refiere a la interconexión entre dos ejes o economías simbólicas articuladas en un sistema único. Por un lado, el eje horizontal caracterizado por relaciones de competencia y alianza entre pares y, por el otro, un eje vertical conformado por las relaciones jerárquicas de exacción de tributo. Siguiendo a Carole Pateman, entiende que "la primer ley universal" no es, a diferencia de lo que sostiene el estructuralismo francés con Lévi-Strauss como su máximo exponente, la ley de intercambio contractual entre pares sino, por el contrario, la ley del status. Es decir, la ley de género. Las personas ocupan posiciones y portan los diacríticos correspondientes en ambos ejes.

La subordinación femenina y la exacción de tributo (sexual, económico, simbólico, étc) por parte de los hombres es lo que les permite su participación en la competencia y alianza. Es la gramática en la que se construye la subjetividad masculina la cual depende del poder de dominación y exhibición de prestigio. Es en esta economía simbólica, por ejemplo, la violación se presenta como ilegal al mismo tiempo que como un "crimen aleccionador" o disciplinador/moralizador: un acto semiótico público de exhibición de fuerza y virilidad (Segato, 2003)

Pensamos, a propósito, en el trabajo de la antropóloga Mariana Gómez (2008) realizado entre las comunidades qom (tobas) del oeste de Formosa en Argentina. En estas comunidades la hegemonía masculina está siendo afectada por la participación de las mujeres en talleres de artesanías como en asambleas públicas. Ante esta nueva situación no sólo se intenta limitar su presencia en espacios políticos de discusión, sino que han aumentado las amenazas de ataques sexuales en el monte donde estas mujeres antiguamente salían a recolectar sin presencia masculina. La serie de representaciones que circulan en torno al posible o presunto ataque sexual refuerzan la naturalización de las diferencias. Se reproducen los cuerpos sexuados tal como los necesita el sistema sexo/género vigente.

Esta amenaza cumple dos funciones. La primera de ellas es la vigilancia sobre el cuerpo femenino y así la consolidación de la sexualidad transaccional en el marco de la relación conyugal. La segunda función es la construcción del mito del espacio doméstico como el único ámbito seguro para la mujer. Además, la contradicción existente entre la violación y el sistema de parentesco y matrimonio que ésta pone en jaque se resuelve acusando a las propias mujeres de ser las incitadoras de tales conductas.

Podemos entender, entonces, que las amenazas y ataques sexuales como la feminización de las conductas sexuales consideradas inapropiadas ("deshonrosas") forman parte de un mismo proceso de corporización y espacialización del género; condicionando específicamente la sexualidad y movilidad femenina en distintos contextos (del Valle, 1991). En este sentido, el principal objetivo de los "crímenes de 
honor" es castigar conductas femeninas consideradas improcedentes o moralmente incorrectas y que, como tales, se perciben como avergonzantes por y para el grupo familiar (nuclear o extenso). Conductas que afectan, supuestamente, el honor de la mujer y, en consecuencia, el de su familia. Estas conductas pueden ser: usar algún tipo de vestimenta considerada inadecuada, su forma de movilidad en el espacio público, cometer adulterio, no aceptar el candidato matrimonial elegido por la familia, mantener algún tipo de vínculo amoroso y/o sexual sin el consentimiento de ésta, haber sido víctima de abuso sexual o incluso querer continuar sus estudios. Es importante señalar que estos crímenes también afectan a todas las personas cuyos cuerpos son feminizados. Por lo tanto, sujetos LGTBQI, al transgredir la masculinidad hegemónica, también son víctimas de esta clase de crímenes.

El honor -ghariat, izzat, o nombre que adquiera según la comunidad o sociedad de la cual se trate- no puede pensarse a expensas de la noción de vergüenza, pudor o modestia exigida a las mujeres (Akpinar, 2003). Ésta, entiende Shelly Feldman (2010), como la moralidad internalizada. La autora, recuperando el concepto de regulación moral de Philip Corrigan (1981), enfatiza la necesaria historización y desnaturalización del nexo honor/pudor (honour/shame complex) y patriarcado. Estudiar como el ethos moral y la normatividad construyen relaciones, organizan rutinas y se expresan en rituales cotidianos de una comunidad o colectividad en cada contexto específico. De esta manera, en debate con el trabajo de Rozario (1992), sostiene que el suicidio femenino en Bangladesh (superior en porcentaje que el masculino y con mayor presencia en comunidades musulmanas) puede estar expresando una forma de agencia de las mujeres que trasciende su victimización y se trate de una "elección" dentro del reducido abanico de posibilidades para evitar castigos corporales, abuso o exclusión social a las que estarían condenadas por transgredir el orden moral imperante (Feldman, 2010).

En este sentido, tal como advierte Hélie (2012), no debemos naturalizar ni esencializar estos crímenes como propios de la comunidad o cultura musulmana. No obstante, sí es necesario advertir las estructuras y discursos que los posibilitan e, incluso, legitiman en determinados contextos. La (re) emergencia de las leyes zina y las praxis discursivas que regulan y criminalizan la moralidad y el comportamiento sexual femenino constituyen, sin lugar a duda, un entorno o una estructura de poder que favorece este tipo de violencia. Esto se conjuga, además, con tradiciones culturales externas a la religión islámica. El islam local en la India, por ejemplo, ha adoptado aspectos del sistema de castas. Del mismo modo, en Pakistán nos encontramos con algunas prácticas consuetudinarias que se superponen a la religión. Tal es el caso del concepto de purdah y la dinámica de género a éste asociada. Purdah significa velo o cortina y se presenta como un código moral de conducta que protege o resguarda el honor de la mujer y el de su familia. Es una institución o un mecanismo de segregación sexual que garantiza la separación entre las esferas de lo público y lo privado; limitando la movilidad y la autonomía de las mujeres.

La habilidad de las mujeres para corporizar la modestia y, en consecuencia, su honorabilidad, refleja o exhibe el capital islámico generizado (islamic gendered capital) que ellas y en especial los hombres (sus esposos, padres, hermanos) poseen (Ramji, 2007, 
p. 1177). Dentro de esta configuración, el islam es movilizado para garantizar la superioridad masculina y restringir así el comportamiento femenino; permitiendo diferenciar entre las mujeres modestas y castas de las promiscuas. En definitiva, sirve para establecer fronteras sociales. En suma, el cuerpo y honor de la mujer como símbolos de la reputación familiar y de la cohesión del cuerpo social.

Abu-Odeh (2011) afirma, por ejemplo, que en las sociedades árabes los "crímenes de honor" han cambiado su función. Antiguamente se usaban para controlar y castigar a los violadores mientras que ahora se emplean para controlar la sexualidad femenina. Esta autora sostiene que estos asesinatos deben explicarse teniendo en cuenta la compleja y triangular interacción entre la violencia social, la violencia estatal y el crimen per se. Explica que la estructura de estos crímenes y su regulación en las distintas normativas dependen de la codificación adoptada por las élites nacionales árabes luego del proceso de independencia y descolonización. Muchos de los sistemas jurídicos de la región son el resultado de una combinación de códigos europeos con la sharía. El famoso artículo 340 del Código Penal de Jordania (modificado en el año $2001^{29}$ ), que exculpaba al asesino que mataba en nombre del honor, tenía dos fuentes legales. La primera era el código penal otomano de 1858 y la segunda fuente era el código penal francés de 1810 (Abu-Odeh, 2011, p. 5). Por consiguiente, para la autora, las élites árabes estaban preocupadas por alcanzar la modernización de sus instituciones y esto se evidenciaba, por ejemplo, en los códigos comerciales; pero, al mismo tiempo, intentaban reproducir la "tradición" como locus identitario de la nación (ibíd., p. 18).

En el contexto pre-nacional, la segregación espacial aseguraba la "virginidad"30 (asociada ésta al honor) pero luego, con el proyecto nacional patriarcal - y ante los cambios de la vida cotidiana y la esfera pública - las mujeres necesitaron o se vieron obligadas a realizar una performance de la virginidad. Muchos Estados mantienen un doble standard: mientras se "modernizan", toleran los "crímenes de honor" o formas de violencia familiar y de género porque son un modo de contener prácticas sexuales "subversivas" (ibíd., p. 41). La virginidad, nos cuenta la autora, es símbolo de respetabilidad y virtud. Delimita, además, las fronteras del cuerpo femenino (Abu-Odeh, 2011, p. 11). Mientras los hombres árabes son vírgenes por "default”, las mujeres deben construir o producir un efecto público de virginidad a partir de su estilo corporal, forma de moverse, de vestirse y de hablar. La virginidad debe ser publicitada a través de su performance. La autora sostiene que del mismo modo que las mujeres han internalizado la mirada censuradora de los hombres, estos han internalizado la mirada de sus compañeros varones (ibíd., p. 15). Las mujeres deben preservar su honor y los hombres defenderlo. Por esta razón, si se descubre que una mujer de la familia lo ha perdido, el hombre sufre detrimento público de su reputación y status de masculinidad.

Por su parte, Sev'er y Yurdakul (1999) analizan los crímenes en nombre del honor en la zona rural de Turquía. Si bien los asesinatos también se comenten en las grandes

\footnotetext{
${ }^{29}$ Incluso el 12 de octubre de 2009 el tribunal penal jordano condenó a un hombre a 15 años de prisión por haber asesinado a su hermana. En: Combatir los crímenes de honor en Europa: Manual para Responsables Políticos, Instituciones y la Sociedad Civil. Informe Fundación Surgir, Edición 2011/2012, p.13

${ }^{30}$ La virginidad de la mujer como propiedad familiar se remonta al Código Hammurabi (1750 a.c apróx.)
} 
ciudades, su incidencia es mayor en las zonas con menores niveles socioeconómicos y de alfabetización, más propensos - señalan - a erróneas o tendenciosas interpretaciones religiosas y culturales. Por otro lado, las autoras -siguiendo a Abu-Lughod ${ }^{31}$ - explican que la noción de honor occidental como virtud o valor es diferente a la concepción existente en Oriente. Por el contrario, en "Oriente" (con esta amplia y cuestionada categoría incluiríamos una diversidad de sociedades y países) el honor es una dimensión integral. Es un pacto social no tangible que remite al status y constituye una dimensión cultural estimada. El problema, advierten las autoras, es cuando se vuelve una obsesión a través de la cual se juzga la conducta de los hombres y, especialmente, de las mujeres.

Sev'er y Yurdakul distinguen distintos términos que se emplean en Turquía para referirse al honor. Sin embargo, se concentran en los vocablos serefo izzat (gloria y status de un hombre) por su carácter androcéntrico y namus o sharam por referirse a un tipo de honor social que se supone las mujeres deben poseer. Refiere a una serie de cualidades morales y físicas que se asocian a la virginidad y la castidad. La mujer debe proteger su namus antes y después del matrimonio porque en caso contrario, avergonzará a toda su familia. Se utiliza la palabra mamussuz para indicar la total pérdida del namus. Se considera, incluso, que dicha impureza se hereda de madre a hijos. En consecuencia, los hombres se sienten legitimados para "limpiar la impureza familiar" y recuperar o mantener su seref.

Si bien las autoras reconocen que la cosmovisión islámica contribuyó en la asociación que las culturas de "Medio Oriente" realizaron entre honor y el cuerpo de la mujer, enfatizan que los femicidios en "nombre del honor" están legitimados, principalmente, por la estructura patriarcal. Aysan Sev'er (2005) afirma que las distintas sociedades del Magreb, Mashrek y el subcontinente indio -más allá de sus diferencias religiosas y culturales- están atravesadas por el denominado "patriarcado clásico"32. Este último se caracterizaría por: la autoridad masculina, la descendencia y herencia patrilineal, la residencia patrilocal, la legitimación del poder masculino y la construcción de tres tipos o modelos ideales de mujer. A saber: hijas vírgenes, esposas modestas y madres sacrificadas por sus hijos (ibid., p. 130-131).

En suma, la familia es considerada como la principal institución social. Por ende, cualquier "transgresión" que modifique o altere el statu quo debe ser castigada. Nuevamente se presenta el cuerpo de la mujer como objeto, primero, de prohibición y tabú y, luego, de sacrificio en favor de la reproducción y consolidación de la solidaridad masculina y la hegemonía heteropatriarcal. No debe asombrarnos, tampoco, que muchos de los "crímenes de honor" escondan casos de incesto y de violaciones en el seno familiar. Cabe preguntarnos si no se trata una forma específica y generizada de economía simbólica de la predación (Fausto, 1999). Es decir, de un consumo productivo de las mujeres en tanto dadoras de tributo (sexual, simbólico, económico, reproductivo) (Segato, 2014, p. $11)$.

\footnotetext{
${ }^{31}$ Se recomienda vívidamente el trabajo de Lila Abu Lughod (1986)

${ }^{32} \mathrm{Al}$ respecto, consúltese el trabajo de Deniz Kandiyoti (1988)
} 
Los "crímenes de honor" no son el resultado de conductas aisladas y esporádicas. Se inscriben dentro de determinadas tradiciones y concepciones culturales para mantener un específico orden de género y, tal vez, garantizar la estructura socioeconómica. Pero, además, a su alrededor se elaboran y reproducen discursos (incluso jurídicos) que relativizan y/o legitiman dichas prácticas. Por consiguiente, no pueden entenderse al margen de otras tecnologías de género.

Como mencionamos en la sección anterior, el Estado pakistaní aprobó, tras una ardua lucha de las organizaciones civiles por los derechos de las mujeres ${ }^{33}$, una Ley de Protección de la Mujer (2006) y en el año 2004 a través del artículo 302 del Código Penal estableció que quien cometa asesinato en "nombre del honor" será sentenciado a cadena perpetua o entre 10 a 25 años de prisión ${ }^{34}$. Sin embargo, las estadísticas de "crímenes de honor" siguen incrementándose. Esto revela lo complejo que es erradicar una práctica cuando el cuerpo social se encuentra estructuralmente atravesado por distintas formas de violencias (simbólica, de género, económica, infantil, institucional) y problemáticas sociales (desigualdad económica, pobreza, vulnerabilidad social, deficiencias sanitarias y educativas, militarización, étc). La ley de protección y el nuevo artículo son un cambio positivo, pero aún insuficiente.

Por un lado, las campañas y programas de prevención, concientización y protección existentes no alcanzan para promover un cambio de paradigma Por el otro, las mismas leyes no han comprendido o, mejor dicho, han ignorado la importancia de los consejos tribales (jirgas) y han preservado el derecho a quisas (compensación monetaria) y diyat (precio de sangre) como forma de sancionar y resolver conflictos. Bazi, Rai y Ali (2006) hablan precisamente del complejo entramado de poder (tensiones y negociaciones) entre el gobierno de las instituciones estatales y el gobierno de las comunidades locales. Es decir, las jirgas en el caso de Pakistán y los panchayats (consejos comunales) en la India.

Mazna Hussain (2006) explica que el concepto de honor en Pakistán está enraizado en la larga tradición preislámica de las sociedades tribales y que en tiempos contemporáneos ha sido reforzado a través de las leyes de familia de origen occidental e islámico. Entiende que, si bien es una práctica más común en áreas rurales que urbanas y en sectores con menores recursos económicos y educativos, también existen casos en las altas esferas sociales. Por ejemplo, en 1999 Samia Sarwar ${ }^{35}$ fue asesinada por sus familiares tras pedir el divorcio de su esposo quien, además, ejercía constantemente violencia contra ella. Samia pertenecía a una familia acaudalada con estudios universitarios de la ciudad de Lahore e, incluso, su madre participó en el ataque que causó su muerte. Como podemos observar estos femicidios atraviesan transversalmente todos los estratos sociales.

\footnotetext{
${ }^{33}$ Recomendamos consultar los trabajos de Shahnaz Khan $(2003,2004,2011)$

${ }^{34}$ En: Combatir los crímenes de honor en Europa: Manual para Responsables Políticos, Instituciones y la Sociedad Civil. Informe Fundación Surgir, Edición 2011/2012, p.13. Y Mir-Hosseini y Hamzić (2010, p. 171)

${ }^{35}$ Por más información sobre el caso se puede visitar: http://www.causeofdeathwoman.com/samia-sarwar
} 
No obstante, Hussain hace hincapié en la forma en cómo la noción de "honor" es manipulada en los contextos tribales para, por ejemplo, resolver rivalidades entre clanes, "deudas de sangre" y el "precio de la novia". Siguiendo a Tahira Khan ${ }^{36}$, contempla la posibilidad de que estos crímenes escondan, entre otras cosas, intereses económicos y financieros. Los matrimonios son calculados y arreglados, especialmente en áreas rurales, para conservar y fortalecer la tenencia o propiedad de las tierras (Hussain, 2006, p. 228). Por lo tanto, cualquier conducta que afecte la estructura socioeconómica - recordemos que la participación de las mujeres en estas comunidades constituye el $50 \%$ de la fuerza de trabajo, aunque su labor no sea remunerada - debe ser sancionada. Por otro lado, Hussain explica que el nuevo artículo contra los crímenes de honor, aunque sea un avance, no contempla - como dijimos anteriormente - las leyes qisas y diyat, ni considera estos asesinatos como crímenes intencionales y premeditados (qatal-i-amd). El preservar las leyes qisas y diyat permite a los miembros de la familia perdonar los asesinatos, recibiendo a cambio compensación económica o iniciando un conflicto en búsqueda del "pago" de la deuda de sangre. De esta manera, el gobierno promueve la privatización de la justicia al tolerar las decisiones extrajudiciales de los consejos tribales y la resolución de los conflictos dentro del ámbito familiar (ibíd., p. 245).

Cuando pensamos en los discursos (religiosos, culturales y jurídicos) que dificultan la erradicación de los "crímenes de honor", recordamos el análisis que Myriam Jimeno $(2002,2004)$ realizó sobre los "crímenes pasionales" en Brasil y Colombia. La autora reflexiona acerca de las representaciones de la emoción amorosa en la acción violenta. Nos explica - retomando los aportes de Whitehead y Bajtín - que la violencia afecta a cada persona en su experiencia única, pero se encuentra anclada fuera de la situación particular en la que ocurre. Es decir, tiene un carácter instrumental (coactivo) al mismo tiempo que su naturaleza es exotópica. La elección de determinado tipo de violencia - la forma en cómo se usa - no depende exclusivamente de una decisión o condición personal sino de la conexión entre ésta y el tejido social. El acto de violencia tiene un marco de significación otorgado por el contexto social en el que ocurre (2002, p. 3). De esta manera, tras recuperar distintas fuentes y el testimonio de hombres responsables de los asesinatos de sus parejas, llega a la conclusión de que el "crimen pasional" no sólo es un tipo de acción violenta sino, además, una construcción cultural que se intenta naturalizar a través de determinados dispositivos práctico-discursivos ambiguos y polimorfos (2004, p. 232).

Frases como "la quería demasiado, fue un momento de emoción", "la maté porque la amaba" muestran que el crimen pasional forma parte de determinada configuración emotiva. A saber: una combinación de elementos subjetivos (emotivos y cognitivos) con temas socialmente compartidos. Esta configuración presenta, según la autora, tres núcleos temático-discursivos: a) la violencia estalla de repente, b) la violencia como acto de locura incontrolable y c) la violencia como consecuencia del exceso de amor (especie de acto poético, dramático y heroico).

\footnotetext{
${ }^{36}$ Se sugiere leer Tahira Khan (2006)
} 
Para Jimeno, como para muchos/as autores/as, la emoción es una dimensión más del pensamiento y, por consiguiente, también depende de la interacción y de los procesos de aprendizaje social. La tradición occidental ha establecido una división entre la razón y la emoción. La primera considerada como una capacidad estrictamente masculina y la segunda asociada directamente a una supuesta naturaleza femenina. Ahora bien, paradójicamente y cómo oportunamente señala la autora, la configuración emotiva posee una doble ambigüedad. Mientras se prohíbe normativamente el uso de la violencia, se disculpa o relativiza en caso de que sea producto de emoción intensa. Por otra parte, al hombre - cuya "superioridad" residiría en su "racionalidad"- se le disculpa el asesinato del "ser emocional" (la mujer) justamente en nombre del amor y los sentimientos que por ella posee. Aquello que supuestamente él más que nadie habría aprendido a controlar.

Salvando las distancias existentes entre los “crímenes pasionales" y los "crímenes de honor" ambos sostienen y refuerzan la idea de que las féminas son patrimonio o posesión de los hombres. Por lo tanto, cualquier transgresión a las normas que ellos impongan o el fin de la relación vincular, los "habilita" a castigarlas; con la muerte si es necesario. Amparándose bajo la trama discursiva que convalida o relativiza estas acciones violentas.

De la misma manera que en los países latinoamericanos es frecuente hallar causas judiciales en la que se emplea el alegato "actuó bajo emoción violenta", tan reproducido, además, por los medios de comunicación; hasta no hace mucho tiempo era común encontrar en algunos países de Asia y África legislaciones que eximían de culpa o disminuían su pena, a aquellos hombres que asesinaban en nombre del honor. Sin ir más lejos, hasta hace poco el artículo 340 del código penal de Jordania establecía que, si un hombre encontraba a su mujer siendo infiel y la mataba, o, encontraba a su hermana o hija en la misma situación y cometía injuria o asesinato, se reduciría considerablemente su pena o se los eximiría de culpa y cargo. Para algunos jueces existían dos víctimas: la mujer asesinada y su femicida (Faquir, 2001, p. 72).

Nos encontramos, parafraseando a Jimeno, ante una configuración moralnormativa [jurídica y consuetudinaria] en la que los "crímenes de honor" se inscriben. $\mathrm{Al}$ respecto, es interesante el ejemplo que brinda Kogacioglu quien nos cuenta que los jueces turcos se definen como los representantes de las instituciones modernas y seculares de un Estado laico; pero, sin embargo, exigen implícita o explícitamente la performance del honor (2004, p. 124). Así mismo, advierte que mientras los jueces aumentan la pena si la víctima es un hombre tras una venganza de sangre (blood feud), no ocurre lo mismo si una mujer es víctima de un "crimen de honor" (ibid., p. 125). A pesar de que Turquía con la intención de ingresar a la Unión Europea - ha revocado el artículo 462 (permitía reducción de la pena en caso de que el asesino tuviese primer grado de parentesco con la víctima) en el año 2004 y en el 2005 haya establecido en el artículo 82.1 que si el crimen cometido se debe a la aplicación de una tradición, el asesino debe ser condenado a cadena perpetua con agravantes; vemos que la forma de castigar las tradiciones varía según el sexo de la víctima en cuestión. 
Preservar el control sobre la conducta femenina, implica garantizar el respeto a la autoridad masculina dentro y fuera del núcleo doméstico, así como también exhibir y consolidar la reputación del clan o grupo familiar en la comunidad. Si algo altera o pone en jaque este orden, es necesario reivindicar o recuperar esa autoridad y prestigio. Si bien el purdah, el namus o el honor sirven para mantener las fronteras entre lo público y lo privado como espacios masculino y femenino respectivamente, podemos observar que la transgresión de la norma por parte de la mujer en cualquiera de estos campos tiene implicancia directa sobre el otro. Basta pensar que la educación de la mujer y su participación en el mercado laboral alteran no sólo la dinámica de las relaciones familiares, sino la estructura política y socioeconómica de muchas comunidades.

La autoridad masculina dentro del espacio doméstico es solidaria a la masculinidad hegemónica en el espacio público. Cuando hablamos de "violencia doméstica", por ejemplo, no nos estamos refiriendo a la violencia que se da en un espacio físico circunscripto (privado) sino, en cambio, aquella que se desarrolla dentro de un determinado contexto de relaciones (personales y familiares). Por esta misma razón, Aujla y Gill (2014), a diferencia de otras autoras, considerarían la violencia en nombre del honor como una forma extrema de violencia doméstica. Existe un continuum entre la esfera de lo público y lo privado. Por consiguiente, no podemos concebirlos como espacios dicotómicos, como tampoco podemos olvidarnos que la violencia de género coexiste con otras formas de violencia intrafamiliar (Daich, 2010, p. 52-53).

El móvil y la forma que adquiere la acción violenta se encuentran, por lo tanto, configurados culturalmente e inscritos en el tejido social. Como afirma Kogacioglu en su análisis sobre los "crímenes de honor", es necesario considerar la multiplicidad y complejidad de instituciones que están involucradas directa e indirectamente y no reducirlos a una mera "tradición cultural" (2004, p. 119). Comprende que la tradición existe, pero considera más importante explorar sus efectos en términos de distribución de poder. Es decir, prestar atención a las prácticas y la división de responsabilidades (ibíd., p. 120). La tradición es evocada por distintos sectores sociales (Estado, comunidades, familia) e instituciones con distintos intereses. Fenómeno que define como tradition effect (121). Por ejemplo, el Estado turco utiliza estratégicamente la "tradición" para decir que la existencia de estos femicidios en el territorio es resultado de la subcultura del pueblo kurdo. Siguiendo a la autora, el foco no tiene que estar puesto en la tradición per se sino en sus framing operations (p. 143). Es decir, en cómo es (re)definida, qué actores sociales e instituciones la usan y quiénes están "autorizados" a hablar por ella.

Sea en el falso nombre del amor, el honor o la tradición, es la mujer la que a través de su propia vida garantiza la de un sistema en el que su pérdida como su existencia parecieran igual de necesarias. El cuerpo de la mujer no es un cuerpo soberano de sí mismo sino, en cambio, un cuerpo sujeto a la soberanía de otros. Otros que lo reclaman, vengan, castigan o sacrifican según así lo requieran o deseen. 


\section{Consideraciones finales}

Indagar y reflexionar sobre los "crímenes de honor" nos plantea el desafío de defender y garantizar los derechos de las mujeres desde una posición que deconstruya el etnocentrismo colonialista, pero sin caer en una visión naif (romantización) relativista. Evitar reproducir, como señalamos en la introducción, los estereotipos que reducen una expresión o manifestación específica de la violencia contra las mujeres como una mera "cuestión cultural" o un "problema religioso". La breve historización y contextualización que esbozamos a lo largo del texto y a través de las discusiones, ejemplos y análisis que plantean diversas autoras remite, precisamente, a la necesidad de abordar la problemática trascendiendo los límites de su exotización.

Las pequeñas digresiones comparativas que realizamos no buscan minimizar la gravedad y el impacto de estos femicidios ni obviar su especificidad. Si no, por el contrario, recuperar aportes antropológicos y de los estudios y teorías feministas sobres otras formas de violencia contra las mujeres, para intentar otras aproximaciones que recuperen aquellos elementos comunes y transversales a todas ellas como un modo de contrarrestar los efectos del etnocentrismo y el orientalismo. Al mismo tiempo que el reconocimiento de los actores, narrativas y factores específicos implicados permita su localización o conocimiento situado. Dar cuenta de ese complejo entramado a través de ejemplos o casos puntuales nos ayuda a evitar el fenómeno anverso; es decir, el relativismo extremo y el occidentalismo. Vimos cómo "la tradición” es instrumentalizada tanto por las comunidades, los medios de comunicación, actores políticos y religiosos, los organismos internacionales o los sistemas judiciales. Observamos cómo las mujeres en tanto cuerpos sexualizados son apropiadas por todos esos actores sociales y asociadas a los modos en que éstos entienden y operan los sentidos que le atribuyen a la tradición.

Es importante, por lo tanto, el camino iniciado por diversas autoras para desnaturalizar y desprivatizar estos femicidios; reconceptualizando los "crímenes de honor" como se hizo, por ejemplo, con los “crímenes pasionales". Por otra parte, creemos que reconocer la dimensión expresiva y exotópica de la violencia como hicimos a través de las contribuciones de distintas autoras a lo largo del texto, no puede eclipsar el hecho de que la violencia no siempre es susceptible a la articulación lingüística ya que experiencia y discurso se encuentran alineados de manera imperfecta a través de zonas de dislocación (Alcoff, 1997, p. 127). El giro discursivo e interpretativo presenta sus alcances y limitaciones. Tal vez sea de utilidad desentrañar la posición empírica que ocupa la mujer en las distintas esferas de la vida social (económica, política, religiosa) como su rol en los modos en cómo cada comunidad se imagina, construye su identidad y memoria. Finalmente, entender que el cuerpo (personal y colectivo; territorial y simbólico) es objeto de restricciones, pero también locus de experiencia y resistencia. La praxis de colectivos y organizaciones como Women Against Fundamentalism ${ }^{37}$, Southall

\footnotetext{
${ }^{37} \mathrm{http}: / /$ womenagainstfundamentalism.org/
} 
Black Sisters ${ }^{38}$, Iranian and Kurdish Women's Rights Organisation ${ }^{39}$ o la conformación de redes de mujeres musulmanas como MUSAWAH ${ }^{40}$ y Women Living under Muslim Laws $^{41}$ son un ejemplo de ello.

Mientras las escena final de $A$ girl in the river nos muestra a un hombre orgulloso del "honor" y "respeto" que la comunidad le confiere por haber intentado matar a su hija (reflejado en el incremento de propuestas matrimoniales desde el episodio), Saba sueña con ser madre de una niña que pueda ser educada, trabajar y concretar todo aquello que se proponga. A la cobardía del padre se le contrapone el deseo de su hija: "Espero que sea una niña porque será valiente (...) Allah es quien decide, pero yo quiero que sea una niña” (traducción propia).

\footnotetext{
${ }^{38} \mathrm{http}: / / \mathrm{www}$. southallblacksisters.org.uk/

${ }^{39}$ http://ikwro.org.uk/

${ }^{40} \mathrm{http}: / /$ www.musawah.org/

${ }^{41} \mathrm{http}: / / w w w . w l u m l . o r g /$
} 


\section{Bibliografía}

Abu-Odeh, L. (2011). Crimes of honor and the construction of gender in Arab societies. Torún: Comparative Law Review, 2(1), 1-47.

Acosta Martín, L. (2013). En torno al género y cuerpo vivido. Las visiones de Pierre Bourdieu e Iris Marion Young. Barcelona: Enrahonar, Quaderns de Filosofía, 51, 95-110.

Akpinar, A. (2003). The honour/shame complex revisited: violence against women in the migration context. Southhampton: Women's studies international forum, 26 (5), 425-442.

Alcoff, L. (1999). Merleau Ponty y la teoría feminista sobre la experiencia. Buenos Aires: Revista Mora, (5),122-138.

Appadurai, A. (2001). Dislocación y diferencia en la economía cultural global. En: Appadurai, A. (2001). La Modernidad Desbordada. Ciudad de México: TrilceFCE, 41-61.

Asad, T. (1993 [1982]). The Construction of Religion as an Anthropological Category. En: Genealogies of Religion: Discipline and Reasons of Power in Christianity and Islam. Baltimore: Johns Hopkins University Press, 27-54.

Aujla, W. y Gill, A. (2014). Conceptualizing 'Honour'Killings in Canada: An Extreme Form of Domestic Violence?. Tirunelveli: International Journal of Criminal Justice Sciences, 9(1), 153-166.

Balibar, E. (2001). Outlines of Topography of Cruelty Citizenship and Civility in the Era of Global Violence. Nueva York: Constellations, 8(1), 15-29.

Bannerji, H. (1994). Textile prison: discourse on shame (lajja) in the attire of the gentlewoman (bhadramahila) in colonial Bengal. Alberta: Canadian Journal of Sociology/Cahiers canadiens de sociologie, 169-193.

Baxi, P., Shirin, R. y Shaheen A. (2006). 'Legacies of common law: 'crimes of honour' in India and Pakistan”. Londres: Third World Quarterly, 27(7), 1239-1253.

Chatterjee, P. (1993). The nation and its fragments: Colonial and postcolonial histories. Princeton: Princeton University Press.

Combatir los crímenes de honor en Europa: Manual para Responsables Políticos, Instituciones y la Sociedad Civil. Informe Fundación Surgir, Edición 2011/2012.

Cooke, M. (2008). Developing the Muslimwoman. Bloomington: Journal of Feminist Studies in Religion, 24(1): 91-99. 
Corrigan, P. (1981). On moral regulation: Some preliminary remarks. Lancaster: Sociological Review, 29: 313-337.

Daich, D. (2010). Narrativas sobre la violencia doméstica. Familias, conflictos y justicia (tesis doctoral). Universidad de Buenos Aires.

Douglas, M. (1973). Pureza y peligro: Un análisis de los conceptos de contaminación y tabú. Madrid: Siglo XXI Editores.

Douglas, M. (1988). Símbolos naturales. Exploraciones en cosmología. Madrid: Editorial Alianza.

Faqir, F. (2001). Intrafamily feminicide in defense of honour: the case of Jordan. Londres: Third World Quarterly, 22(1), 65-82.

Fausto, C. (1999). Of Enemies and Pets: Warfare and Shamanism in Amazonia. Nueva York: American Ethnologist, 26 (4), 933-956.

Feldman, S. (2010). Shame and honour: The violence of gendered norms under conditions of global crisis. Southampton: Women's Studies International Forum, 33 (4): 305-315.

Fraser, N. (2008). La justicia social en la era de la política de identidad: Redistribución, reconocimiento y participación. Buenos Aires: Revista de Trabajo, 4(6), 83-99.

Frigolé, J. (2009). Genocidio y Procreación. Ciudad de México: Alteridades, 19 (38), 95105.

Galtung, J. (1990). Cultural Violence. Londres: Journal of Peace Research, 27(3), 291.305 .

Gill, A. y Brah, A. (2014). Interrogating cultural narratives about 'honour'-based violence. Thousand Oaks: European Journal of Women's Studies, 21(1), 72-86.

Gill, A., Strange, C. y Roberts, K. (eds.) (2014). Honour Killing and Violence: Theory, Policy, and Practice. Londres: Palgrave Macmillan.

Gill, A. (2013). Feminist reflections on researching so-called "honour'killings". Berlín: Feminist Legal Studies, 21(3), 241-261.

Gill, A.; Begikhani, N. Y Hague, G. (2012). Honour-based violence in Kurdish communities. Southampton: Women's Studies International Forum, 35(2):75-85.

Gill, A. (2006). Patriarchal violence in the name of 'honour'. Tirunelveli: International Journal of Criminal Justice Sciences, 1(1), 1-12.

Godelier, M. (1978). Poder y Lenguaje. Reflexiones sobre los paradigmas y las paradojas de la legitimidad de las relaciones de dominación y opresión. Franklin: Comunications, (28). 
Gómez, M. (2006). El cuerpo por asalto. La amenaza de la violencia sexual en el monte entre las mujeres tobas del oeste de Formosa. En: Silvia H. (coord.) Mujeres Indígenas en la Argentina. Cuerpo, Trabajos y Poder. Buenos Aires: Biblos.

Grzyb, M. (2016). An explanation of honour-related killings of women in Europe through Bourdieu's concept of symbolic violence and masculine domination. Southampton: Current sociology, 64(7), 1036-1053.

Hefner, R. (ed.) (2011). Sharia Politics- Law and Society in the Modern Muslim World. Bloomington: Indiana University Press.

Hélie, A. (2012). Communities and Control Sexuality. Tacking so called honour crimes in muslim contexts. En: Hélie, A. (ed.) Sexualities, Culture and Society in Muslims Contexts. Londres: Journal of WLUML, Dossier 32-33.

Hoodfar, H. (1998). Muslim Women on the threshold of the Twenty First Century. Londres: WLUML, Dossier 21.

Hussain, M. (2006). Take My Riches, Give Me Justice: A Contextual Analysis of Pakistan's Honor Crimes Legislation. Cambridge: Harvard Journal of Law and Gender, 29, 223-246.

Imam, A. (1997). The Muslim Religious Right (Fundamentalists) and Sexuality. Londres: WLUML, Dossier 17.

Jimeno, M. (2002). Crimen pasional: con el corazón en tinieblas. Madrid: Serie Antropológica, 323.

Jimeno, M. (2004). Crimen Pasional: contribución a una antropología de las emociones. Universidad Nacional de Colombia.

Keeping, J. (2012). Honour Killings in Canada: What needs to be said? What needs to be done?. En: MacIntosh, H. y Shapiro, D. (Eds.) (2012). Gender, Culture and Religion: Tackling some difficult questions. Nueva York: Sheldon Chumir Foundation for Ethics in Leadership, 11-20.

Kogacioglu, D. (2004). The tradition effect: Framing honor crimes in Turkey. Indiana: Differences: A journal of feminist cultural studies, 15(2), 119-151.

Kulczycki, A. y Windle, S. (2011). Honor killings in the Middle East and North Africa: A systematic review of the literature. Southampton: Violence against women, 17(11), 1442-1464.

Magallón Portolés, C. (2005) Epistemología y violencia. Aproximación a una visión integral sobra la violencia hacia las mujeres. Alicante: Feminismo/s, 33-47.

Marty, M. y Appleby, S. (1993). Fundamentalism and Society. Reclaiming the Sciences, the Family an Education. Chicago: The University of Chicago Press. 
McNay, L. (2000). Gender and Agency. Reconfiguring the subject in feminist theory and social theory. Nueva Jersey: Blackwell Publishers Inc.

Meetoo, V. y Mirza, H. S. (2007). There is nothing 'honourable' about honour killings: Gender, violence and the limits of multiculturalism. Southampton: Women's Studies International Forum, 30(3), 187-200.

Messick, B. (1993). The Calligraphic State: Textual Domination and History IN A Muslim Society. Berkeley: University of California Press.

Miguel Álvarez, A. (2003). El movimiento feminista y la construcción de marcos de interpretación. El caso de la violencia contra las mujeres. Córdoba: Revista Internacional de Sociología, 35, 127-150.

Mir-Hosseini, Z. y Vanja H. (eds.) (2010) Control and Sexuality: The Revival of Zina Laws in Muslim Contexts. Nottingham: The Russell Press.

Moi, T. (2011). Apropiarse de Bourdieu: la teoría feminista y la sociología de la cultura de Pierre Bourdieu. El feminismo como critique. Buenos Aires: Feminaria, 26/27, 1-20.

Mojab, S. y Amir, H. (2002). The Politics and Culture of "Honour Killing": The Murder of Fadime Šahindal. Nueva Escocia: Atlantis: Critical Studies in Gender, Culture \& Social Justice, 56-70.

Montenegro, S. (2007). Hacia una sacralización de la política: Reflexiones sobre las perspectivas de análisis del Islam Político. Buenos Aires: Sociedad y Religión, $17(28 / 29)$.

Nagel, J. (2003). Fronteras etnosexuales en zonas de guerra. Bogotá: Nómadas, 19, 188199.

Nasrullah, M., Sobia H. y Kristin, C. (2009). The epidemiological patterns of honour killing of women in Pakistan. Oxford: The European Journal of Public Health, $1-5$.

Pace, E. (2006). Política de redención y redención de la política. São Paulo: Ciencias Sociales y Religión, 8, 31-40.

Perrot, M. (1998). El feminismo critica: Lamentamos su ignorancia. Guadalajara: La Ventana, 8, 325-328.

Ramji, H. (2007) Dynamics of Religion and Gender amongst Young British Muslims. Thousand Oaks: Sociology, 41(6), 1171-1189.

Rozario, S. (1992). Purity and communal boundaries: women and social change in a Bangladeshi village. Londres: Zed Books.

Russel, D. y Roberta H. (eds.) (2006) Feminicidio: Una perspectiva global. Ciudad de México: UNAM. 
Sanberg, R. y Janssen, J. (2018). The spectacle of the feminine Other: Reading migrant women's autobiographies about honour-based violence. Southampton: Women's Studies International Forum, 68: 55-64.

Segato, R. (2014). Las nuevas formas de la guerra y el cuerpo de las mujeres. Madrid: Ediciones Tinta Limón y Pez en el Árbol.

Segato, R. (2012). Femigenocidio y feminicidio: una propuesta de tipificación. Buenos Aires: Revista Herramienta, 49.

Segato, R. (2006). ¿Qué es un feminicidio? Notas para un debate emergente. Buenos Aires: Revista Mora, 12.

Segato, R. (2004). Territorio, Soberanía y Crímenes de Segundo Estado: La escritura en el cuerpo de las mujeres asesinadas en Ciudad Juárez. Ciudad de México: Serie Antropología, 362.

Segato, R. (2003). Las estructuras elementales de la violencia. Ensayos sobre género entre la antropología, el psicoanálisis y los derechos humanos. Buenos Aires: Universidad Nacional de Quilmes.

Sev'er, A. (2005). In the name of fathers: honour killings and some examples from Southeastern Turkey. Nueva Escocia: Atlantis: Critical Studies in Gender, Culture \& Social Justice, 30(1), 129-145.

Sev'er, A. \& Gökçeçiçek, Y. (1999). Culture of honor, culture of change a feminist analysis of honor killings in rural Turkey. Thousand Oaks: Violence against women, An International and Interdisciplinary Journal, 7(9), 964-998.

Sharp, J. (2005). Guerra contra el terror y geopolítica feminista. Bogotá: Tabula Rasa.

Stanley, R. (2007). Violencia sexualizada en tiempos de guerra: discursos hegemónicos y orden de género. Buenos Aires: Cuadernos de Antropología Social, 25, 7-27.

Tarducci, M. (2002). Servir al marido como al señor: Las mujeres pentecostales desde una perspectiva de género (tesis doctoral). Facultad de Filosofía y Letras, Universidad de Buenos Aires.

Wood, E. (2009). Violencia sexual durante la guerra hacia un entendimiento de la variación. Bogotá: Análisis Político, 66, 3-27.

Yegenoglu, M. (1998). Colonial fantasies: Towards a feminist reading of Orientalism. Cambridge: Cambridge University Press.

Young, I. M. (2003). The logic of masculinist protection: reflection on the Current Security State. Chicago: Journal of Women in Culture and Society, 29(1).

Yuval-Davis, N. (1997). Gender and nation. Thousand Oaks: Sage. 
Zine, J. (2006). Unveiled Sentiments: Gendered Islamophobia and Experiences of Veiling among Muslim Girls in a Canadian Islamic School. Londres: Equality and Excellence in Education, 39, 239-252.

Zine, J. (2008). Muslim Women and the politics of representation. Bloomington: Journal of Feminist Studies in Religion, 24. 